\title{
A Comparative Study of Fabrication of Sand Casting Mold Using Additive Manufacturing and Conventional Process
}

\author{
Nishant Hawaldar, Jing Zhang* \\ Department of Mechanical and Energy Engineering, Indiana University - Purdue University \\ Indianapolis, Indianapolis, IN 46202 \\ *Corresponding author: jz29@iupui.edu
}

\begin{abstract}
In this study, two processes to fabricate casting mold, conventional sand casting process and additive manufacturing or $3 \mathrm{D}$ printing process, are comparatively investigated. The two processes were compared in terms of their weight saving, surface finish, design allowance, and fettling work. The results show that there are significant advantages in using additive manufacturing in the production of mold. The 3D printed molds provide substantial saving of sand used, design allowances and fettling work. The mechanical properties of 3D printed molds are also higher than the conventional ones due to good bonding strength during $3 \mathrm{D}$ printing.
\end{abstract}

Keywords: additive manufacturing; mold; sand casting; 3D printing; binder jetting

This is the author's manuscript of the article published in final edited form as:

Hawaldar, N., \& Zhang, J. (2018). A comparative study of fabrication of sand casting mold using additive manufacturing and conventional process. The International Journal of Advanced Manufacturing Technology, 97(1), 1037-1045. https://doi.org/10.1007/s00170-018-2020-z 


\section{INTRODUCTION}

\subsection{Conventional sand casting versus casting using 3D printed molds}

\subsubsection{Conventional sand casting}

Sand casting process is one of the expandable-mold methods, and is considered the most widely used casting process due to its economical characteristics. This process is used to produce approximately $70 \%$ of all metal casting [1]. The conventional sand casting process starts with pattern making. The patterns are usually made of wood, metal, plastic or other materials. The cavity is formed out of sand by means of pattern and has a replica of the shape of the part to be cast. Pouring molten metal in the cavity gives the final metal cast [2].

Considering shrinkage of the metal during solidification phase, shrinkage allowance is provided to a pattern. Shrinkage allowance increases the final dimension of the cast. Interior geometry of the part is determined by means of a core which is placed inside the mold cavity. A core box is required to make a core which is usually the replica of core itself [3]. Pattern making and mold and core box making come under casting tooling. Apart from these two tooling features, sand casting includes making of prints for cores, pouring basin, sprue, runner and risers, and feed aids [4]. Generalized steps in conventional sand casting are shown in Figure.1. In general, sand casting has a low production rate because in order to remove the casting part, and the sand mold needs to be broken [5].

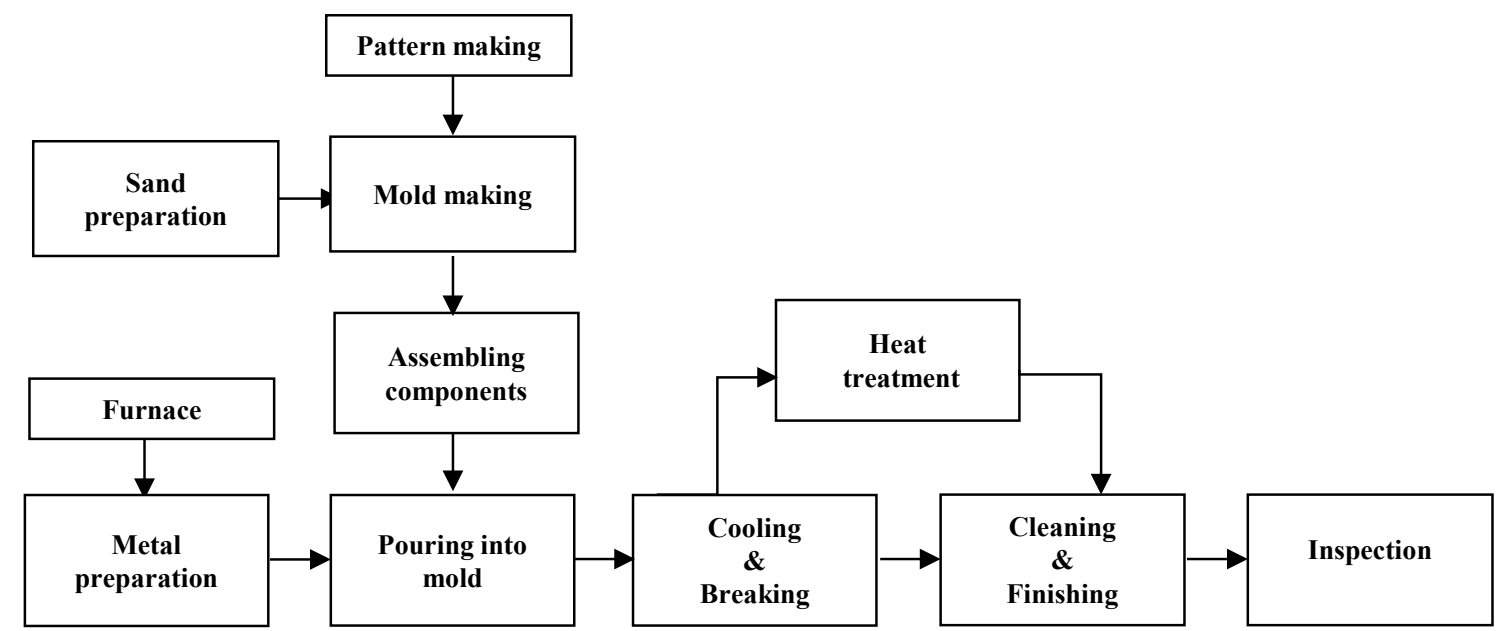

Fig.1: Generalized steps in conventional sand casting process 


\subsubsection{D printed molds for casting}

As discussed above, many of general steps in traditional sand casting process, including pattern, mold, core and core box are derived from the part geometry, followed by modification to incorporate various allowances. These steps provide new opportunity for adopting additive manufacturing or $3 \mathrm{D}$ printing technique into the sand mold fabrication. Additionally, it is very challenging to fabricate a metal casting with complex geometries using the conventional casting process. Therefore, the geometric freedom offered by AM technology is an important asset that can be used in combination with conventional processes [6]. In contrast to the long history of conventional sand casting process, additive manufacturing has emerged only a few decades ago. Many of the applications for 3D printed molds are providing flexible tooling for conventionally designed castings.

Some pattern making shops have started adopting this AM technology as a better method for testing part and pattern designs. Different shrinkage and draft allowances along with gating systems can be optimized. Once the design is finalized, a durable pattern could be manufactured using conventional casting means [7].

Pattern making requires skilled labor but 3D printing has simplified pattern making which was hitherto a skilled job and depended on artisans.[8] Now-a-days different additive manufacturing processes like Binder Jetting (BJ), Laminated Object Manufacturing (LOM), Fused Deposition Modeling (FDM) and Selective Laser Sintering (SLS) can produce components strong enough to replace the conventional wooden patterns [9]. Recently, SLS and BJ processes have been used to directly manufacture silica sand molds and cores by selectively jetting binder into a powder bed of conventional foundry sand. In some cases, the same BJ process is used to fabricate master pattern which generally requires in mass production [10]. 3D printers are available which can print a sand mold directly from CAD files in a matter of hours. As a result, sand mold and cores can be produced without the need of patterns (i.e., Patternless Molds). The surface finish and mechanical properties achieved using printed sand molds are consistent with conventional sand castings[11]. 
The generalized steps of sand casting using 3D printed molds are shown in Figure 2. Comparing the step chart in Figure 1, the steps of pattern making and mold making can be replaced by 3D CAD data and 3D printing of molds and core.

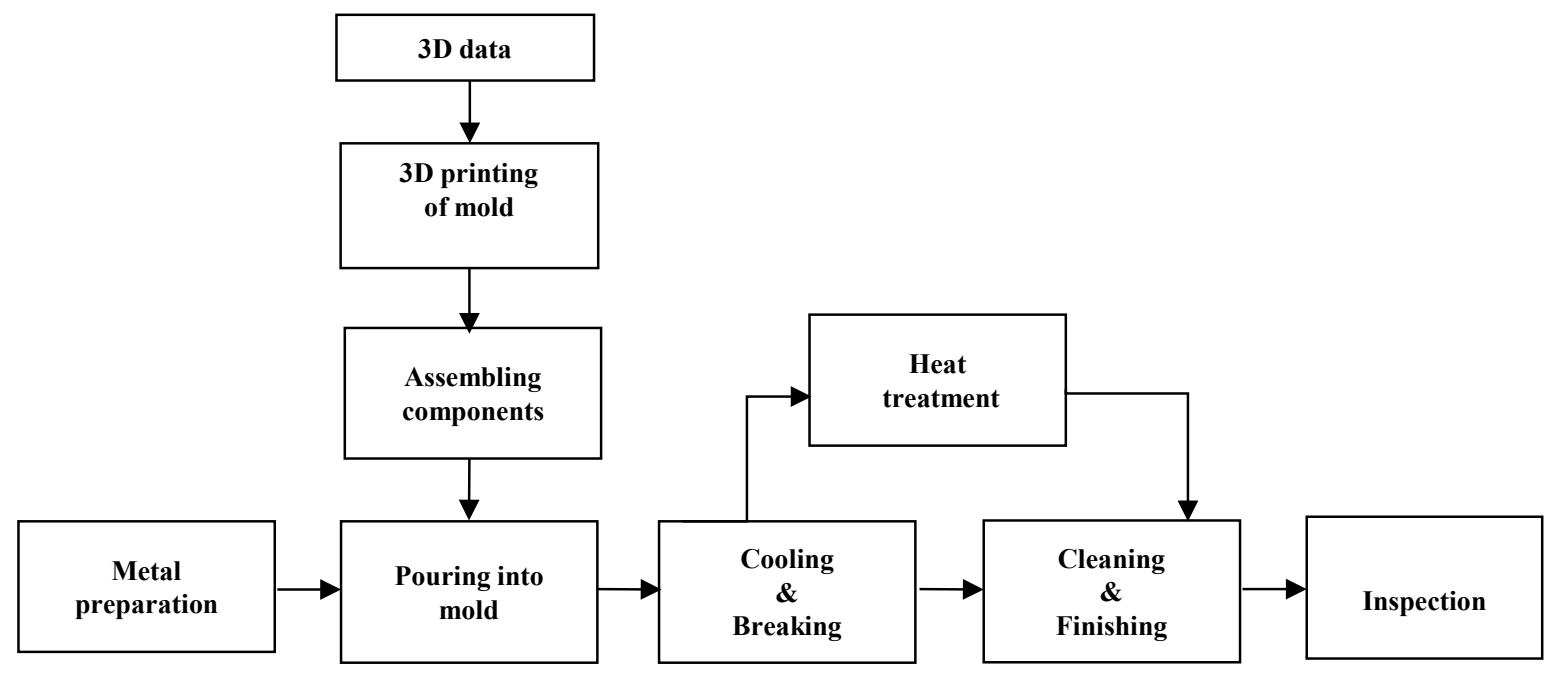

Fig.2: Generalized steps in casting process using 3D printed molds.

\subsection{Materials for traditional sand casting and 3D printed casting molds}

The traditional sand casting process used for this study was no-bake, also known as 2-part sand casting. The grain size of the sand used for no-bake sand casting process is around 200-220 $\mu \mathrm{m}$ with AFS (American Foundry Society) fineness number 60-65. In this process, chemical binders are used to bond the molding sand. The chemical binder and catalyst are added to sand and this mixture is blended in a mixer. Cope and drag are individually filled with this molding sand which forms a compacted, strong and dense mold. Furan resin (Hüttenes-Albertus GmbH) was used as a binder with Sulfonic acid (Hüttenes-Albertus $\mathrm{GmbH}$ ) as acid catalyst. The exothermic polycondensation caused by addition of an acid catalyst to a furan resin causes, hardening of the binder [12]. The curing mechanism is shown in Figure 3.

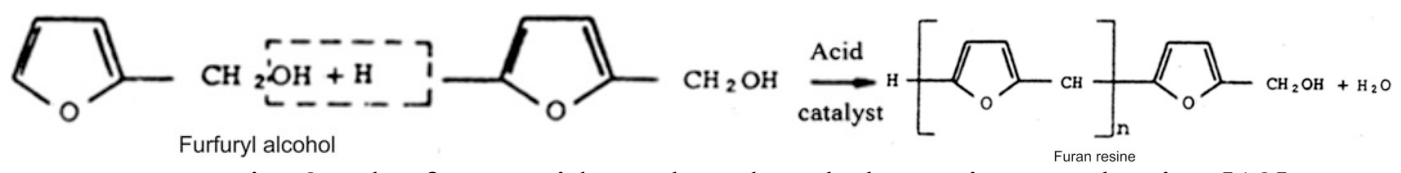

Fig. 3: The furan acid-catalyzed no-bake curing mechanism[12]. 
The mold material used for 3D printed molds is the proprietary Furan Direct Binding (FDB) sand developed by Voxeljet, $\mathrm{GmbH}$ for a range of its printers as a mold material for making molds and cores for casting applications. The FDB sand consists of silica sand (GS14, Voxeljet GmbH) with a grain size $140 \mu \mathrm{m}$. The cold hardening furan resin is used as a binder for binding the silica sand. The binder content was between $0.9-2.0 \mathrm{wt} \%[13]$.

The objective of the paper is provide a comparative study of mold fabrication between traditional sand casting process and new developed 3D printing process. This paper is arranged as follows. In Section 2, the process of 3D printed mold and core will be presented due to its uniqueness, followed by assembly of the mold components. In Section 3 results and discussion, the weight, surface finish, design allowance, fettling work of the two processes will be compared. Finally, the conclusion is given in Section 4.

\section{EXPERIMENTAL PROCESS FOR SAND PRINTING}

\subsection{D printing of mold components}

In this study, a binder jetting 3D printer (VX500, Voxeljet, Germany) was used to 3D print the mold and core of a pump bowl. The multi-jet print head enables to achieve resolution of $600 \mathrm{dpi}$ with a $80 \mu \mathrm{m}$ layer thickness. Effective and continuous operation through rugged design can be achieved using VX500 for high quality components. The unprinted sand particle is recyclable which can be recycled for next projects [14].

The 3D CAD model files (Figure 4) are generated in Creo2.0. The Creo file is then converted into .stl format. Then.stl file is given as input to the 3D printer. The Furan Direct Binding sand mentioned in Section 1.2 is spread over the bed and print-head sprays binder through jets. Layer by layer printing of each component is carried out into the printer. 


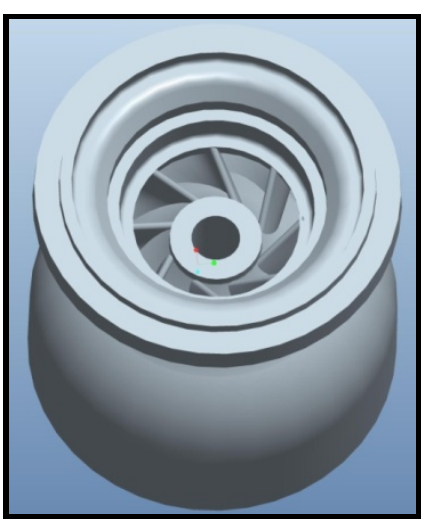

(a)

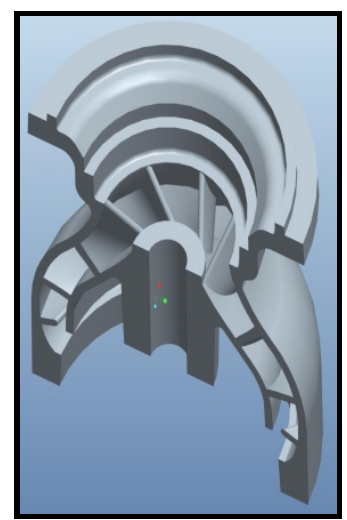

(b)

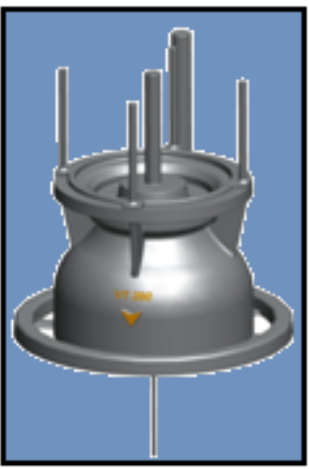

(c)

Fig.4: 3D CAD model of (a) casting bowl, (b) cross-sectional view of the bowl, (c) gatting system

Figure 5 shows the schematic diagram of binder jetting process used in the printer. Traditional inkjet print head is used to form one cross-sectional layer of the part, after a layer of sand is printed. The the powder bed lowers, and fresh sand is spread over the bed using a roller. In this manner the process repeats until desired height is achieved. After the mold is printed, the excess sand is removed using compressed air or vacuum.

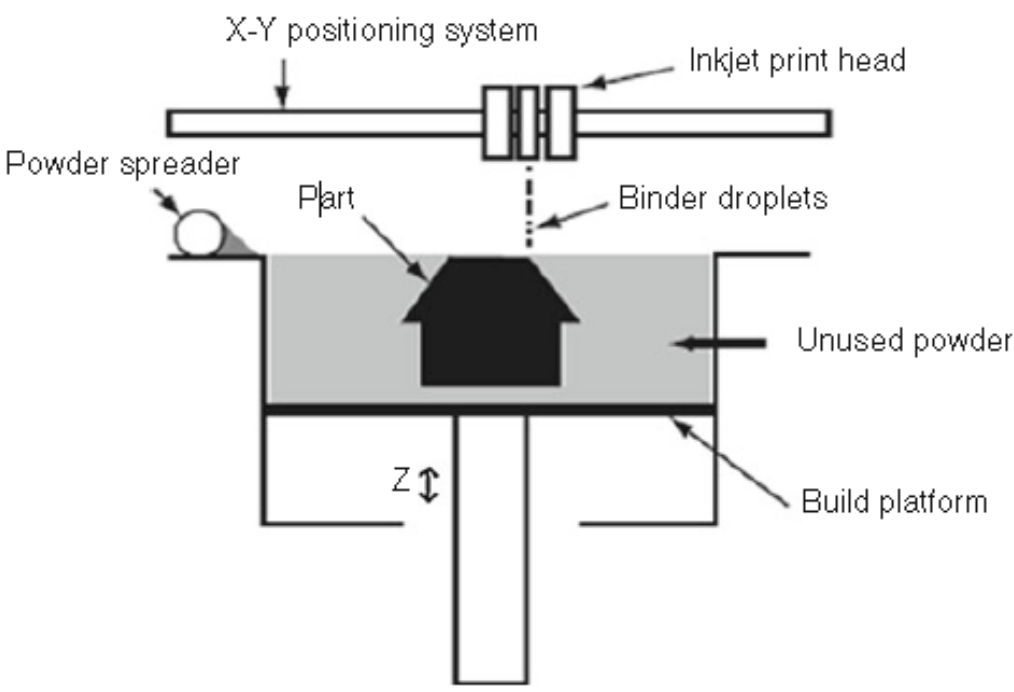

Fig.5: Schematic diagram of the binder jetting $(\mathrm{BJ})$ process

In this study, the parts of mold are cope and drag which are printed individually along with the inside core. The printed parts are shown in Figure 6. The cope and drag are the top and bottom parts of the mold assembly. In some cases, the mold assembly is done in three parts, the middle 
part is called cheek. The gating system is designed along with the mold parts in Creo, as shown in Fig. 6 (c). The gating system includes runners and risers along with down sprue. Core prints are also provided which forms a seat in the mold on which the sand core rests during pouring of the mold. The molds also have prints on four corners to ease assembly.

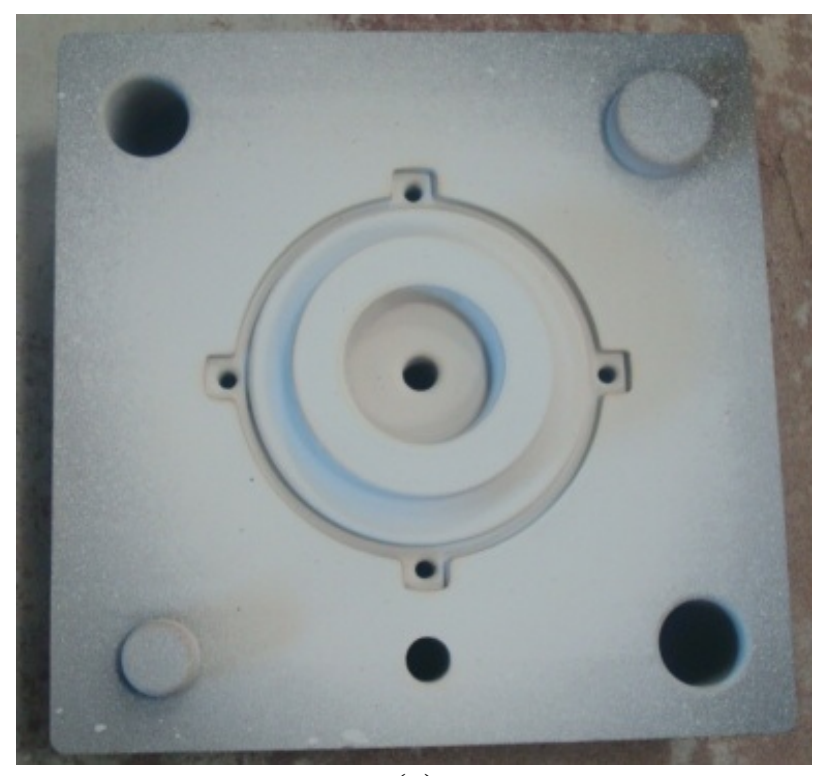

(a)

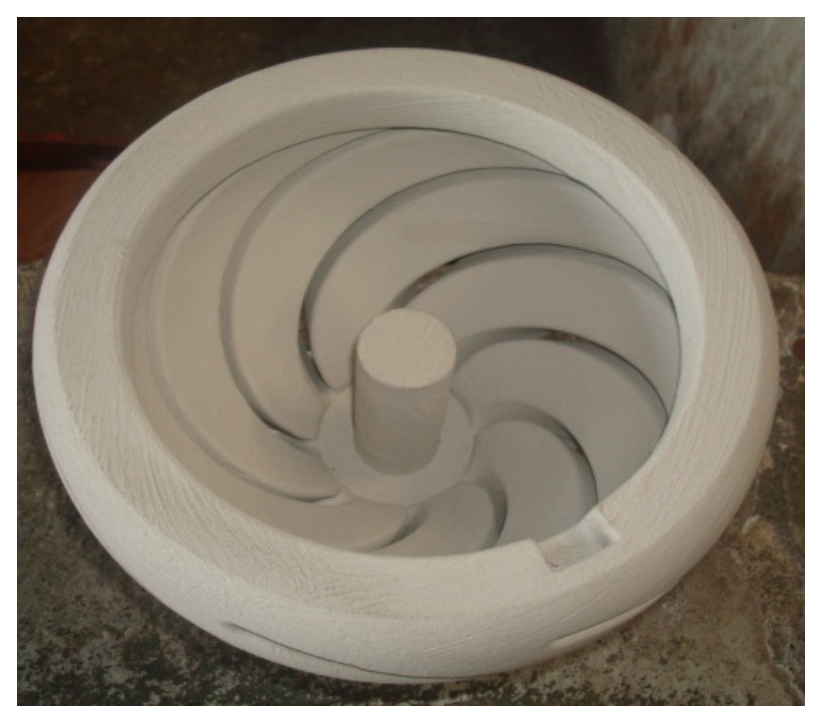

(c)

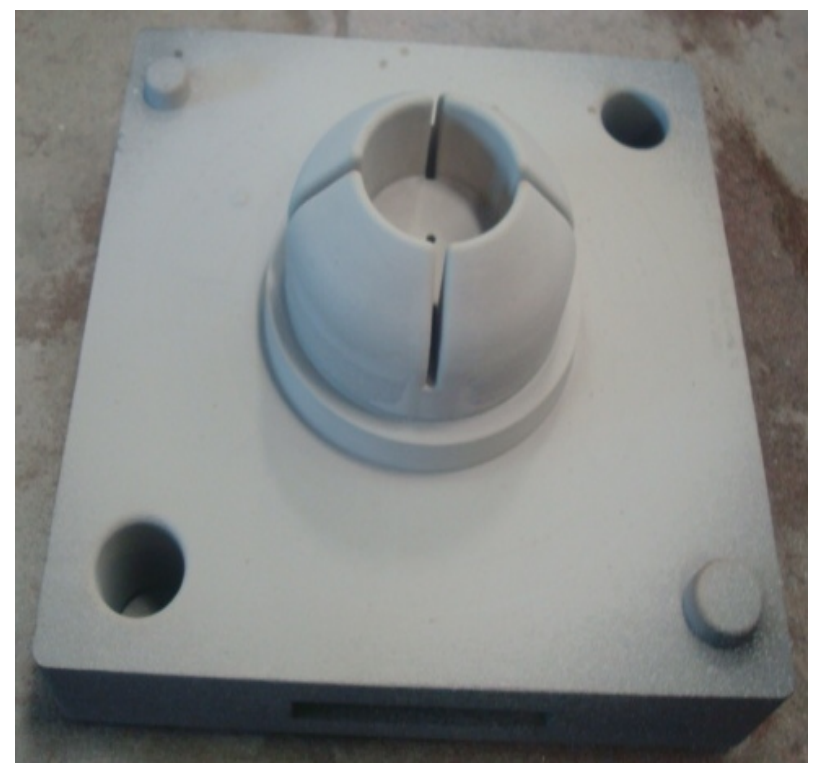

(b)

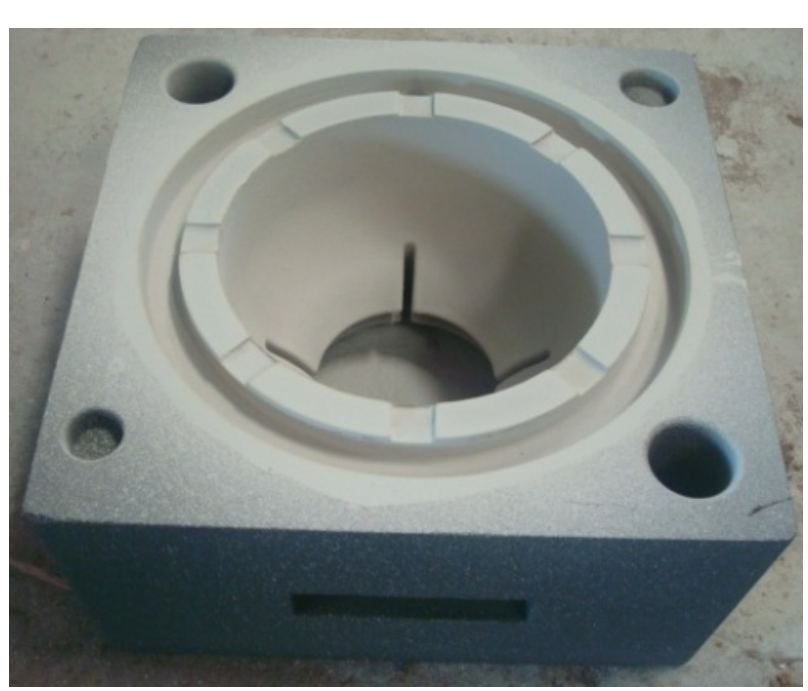

(d)

Fig.6: 3D printed mold components: (a) drag, (b) cope, (c) core, (d) cheek 


\subsection{Assemble of 3D printed mold and core}

The assembly of mold is somewhat same as conventional sand casting process. Figure 7 shows the assembly steps for mold and core. First the bottom part i.e. drag is kept on ground and core is slowly mounted on it. Core prints provided helps in self alignment with the drag. After this the center part of mold, i.e., cheek is mounted on core. Through bars are provided for better alignment and support the mold assembly. At last the top most part, i.e., cope is mounted on cheek which has pouring well on top of it.

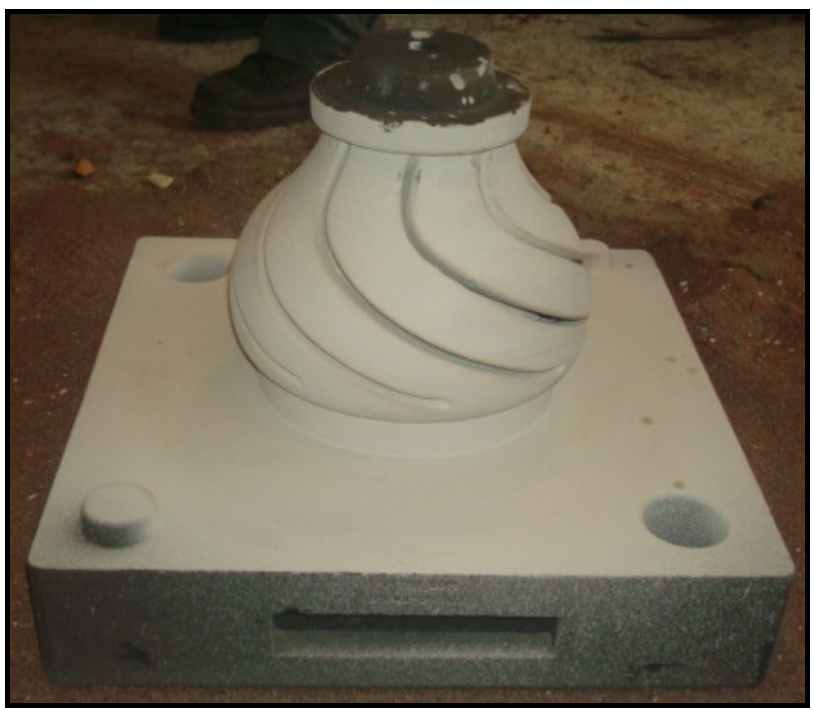

(a)

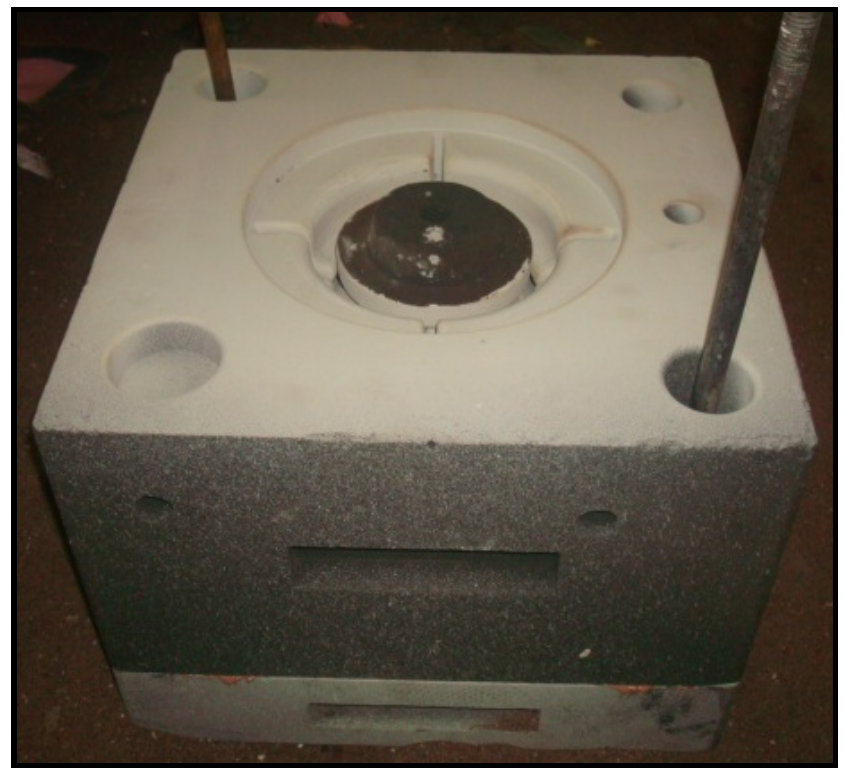

(c)

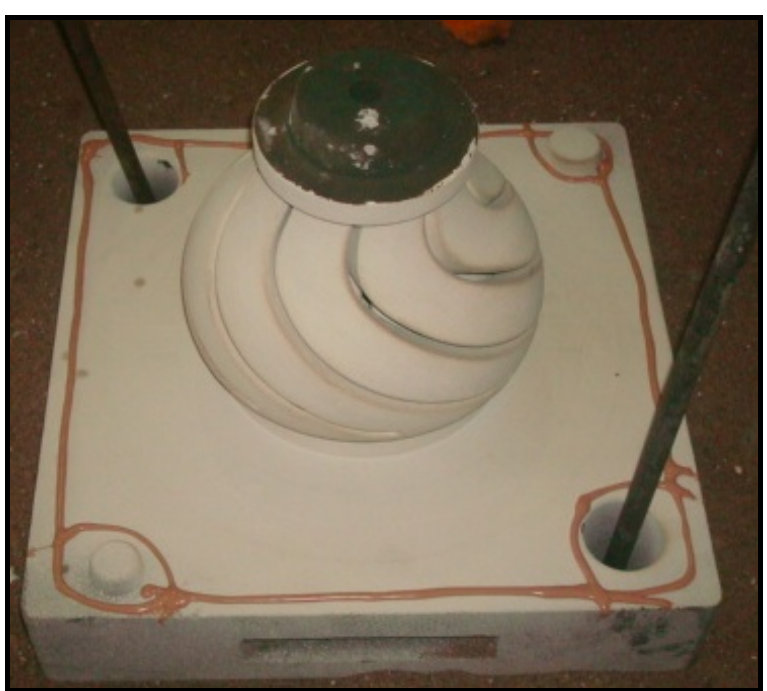

(b)

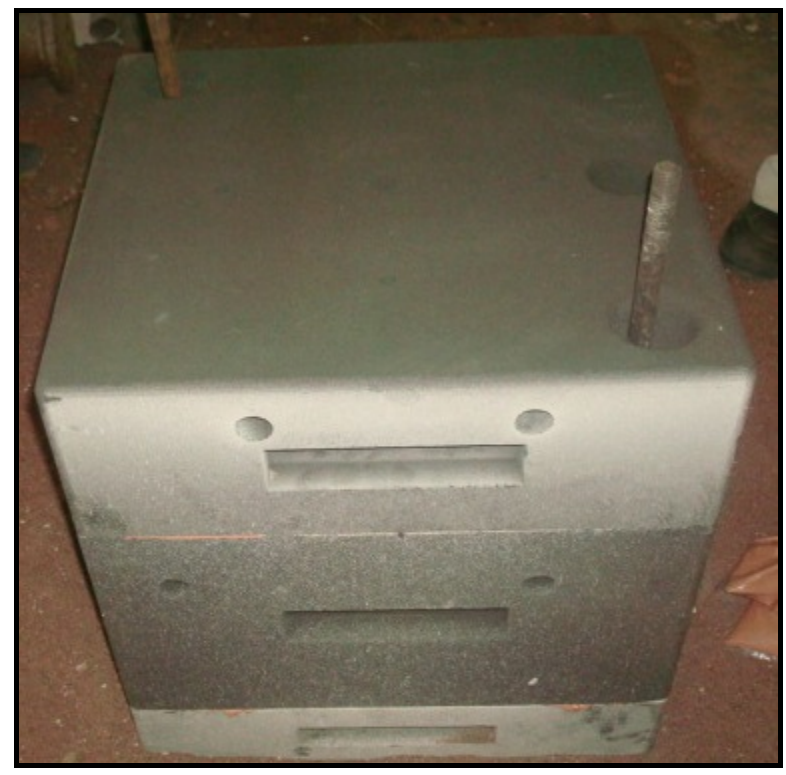

(d) 
Fig.7: Assembly of 3D printed mold components: (a) core is mounted on drag, (b) through bars are placed in holes, (c) cheek is placed over drag, (d) cope is mounted over cheek

\subsection{Metal preparation and pouring}

Pump bowl is a part of vertical turbine pump which act as a diffuser with vanes cast integrally. The impeller is coupled with the bowl through pump shaft bearings. The pump bowl specifications are shown in Table 1. The molten cast iron (FG260) is prepared into a furnace and at $1400{ }^{\circ} \mathrm{C}$ is poured in the pouring well using preheated ladle.

Table 1: Pump bowl specifications

\begin{tabular}{|c|c|}
\hline Casting weight & $21.70 \mathrm{Kg}$ (CAD Input) \\
\hline Casting material grade : & Cast Iron( FG260) \\
\hline No of Vanes & $8 \mathrm{nos}$ \\
\hline Vane thickness & $4 \mathrm{~mm}$ \\
\hline Overall size (diameter $x$ height) & $247 \mathrm{~mm} \times 220 \mathrm{~mm}$ \\
\hline Wall thickness & $7 \mathrm{~mm}$ \\
\hline
\end{tabular}

The mold is allowed to cool after pouring of molten metal. Mold is broken using a hammer, and the final cast is removed and send to fettling shop for removing runner and risers.

\section{RESULTS AND DISCUSSION}

\subsection{Weight of the components}

To compare the weight saving, a weighing scale was used to measure the weights of components. The weight reduction is achieved for all parts i.e. cope, cheek (middle part), drag, and core. As shown in Table 2, the amount of sand used in conventional sand casting process for making mold was $301 \mathrm{~kg}$ and in 3D printing process it was $99 \mathrm{~kg}$ which is also less, compared to conventional sand casting. The amount of sand saved was $202 \mathrm{~kg}$ which results in $67.11 \%$ saving. The core in case of conventional sand casting requires three parts to make and then need to assemble it to form the final core. The core for the pump bowl has 8 vanes, and each vane 
need to be made separately using special core boxes. Then single vanes are glued to main core and dome core. At last the prints are glued for better seating of core into cavity.

Table 2: Weight comparison for conventional sand casting mold and 3D printed mold

\begin{tabular}{|c|c|c|c|c|}
\hline \multicolumn{5}{|c|}{ MOLD } \\
\hline $\begin{array}{c}\text { Mold } \\
\text { Component }\end{array}$ & $\begin{array}{c}\text { Sand used in conventional } \\
\text { sand casting } \\
(\mathrm{Kg})\end{array}$ & $\begin{array}{l}\text { Sand used in 3D } \\
\text { printing } \\
(\mathrm{Kg})\end{array}$ & $\begin{array}{l}\text { Sand saving } \\
\text { (Kg) }\end{array}$ & $\begin{array}{c}\text { Weight saving } \\
\text { percentage }(\%)\end{array}$ \\
\hline Cope & 80 & 34 & 46 & 57.5 \\
\hline Cheek & 113 & 40 & 73 & 64.6 \\
\hline Drag & 108 & 25 & 83 & 76.85 \\
\hline Total & 301 & 99 & 202 & 67.11 \\
\hline \multicolumn{5}{|c|}{ CORE } \\
\hline $\begin{array}{c}\text { Core } \\
\text { Component }\end{array}$ & $\begin{array}{c}\text { Sand used in conventional } \\
\text { sand casting. } \\
\text { (Kg) }\end{array}$ & $\begin{array}{l}\text { Sand used in3D } \\
\text { printing } \\
(\mathrm{Kg})\end{array}$ & $\begin{array}{c}\text { Sand saving } \\
\text { (Kg) }\end{array}$ & $\begin{array}{l}\text { Weight saving } \\
\text { percentage }(\%)\end{array}$ \\
\hline Main core & 2.8 & \multirow{3}{*}{3.3} & \multirow{3}{*}{4.4} & \multirow{3}{*}{57.14} \\
\hline Print core & 0.2 & & & \\
\hline Dome core & 4.7 & & & \\
\hline Total & 7.7 & 3.3 & 4.4 & 57.14 \\
\hline \multicolumn{5}{|c|}{ Cast Pump Bowl } \\
\hline \multirow[t]{2}{*}{ Usage of metal } & $\begin{array}{c}\text { Casting weight } \\
\text { (Kg) }\end{array}$ & $\begin{array}{c}\text { Casting weight } \\
\text { (Kg) }\end{array}$ & $\begin{array}{c}\text { Metal saving } \\
(\mathrm{Kg})\end{array}$ & $\begin{array}{c}\text { Weight saving } \\
\text { percentage (\%) }\end{array}$ \\
\hline & 32 & 23.4 & 8.6 & 26.88 \\
\hline
\end{tabular}

Making this core by conventional method requires around $7.7 \mathrm{Kg}$ of sand, but on the other hand the $3 \mathrm{D}$ printed core which was made in single piece required $4.4 \mathrm{Kg}$. the sand percentage saved by going with 3D printing process saved $57.14 \%$ of sand.

Conventionally made pump bowl weighs $32 \mathrm{Kg}$ and the pump bowl made using 3D printed mold and core weighs $23.4 \mathrm{Kg}$. The designed weight of the pump bowl is $21.70 \mathrm{Kg}$ which is calculated using total volume of metal poured into cavity. The final weight of casted pump bowl using 3D printed mold and core is close to the calculated design weight. So using 3D printed mold and cores for fabricating pump bowl is also effective in terms of final cast weight of pump bowl, as it saves $8.6 \mathrm{Kg}$ of metal which results in $26.88 \%$ of metal saving. 


\subsection{Casting surface finish bonding strength}

The fabricated pump bowls using the two processes are shown in Figure 8, and the side views are given in Figure 9. According to ISO standard the approximate values of surface roughness are from N1 to N12 and tolerance on dimensions typically obtained with different manufacturing processes as available in Ref [5]. The desired surface roughness for this pump bowl is N9 considering hydraulic efficiency and application where the vertical turbines pump will be installed. Phase II SRG 4000 Surface Roughness Tester was used to measure the surface roughness of the pump bowl. Sand particle size and distribution plays a vital role in good surface finish. The better surface finish is produced due to fine grain size of sand but on the other hand it reduces the permeability of the sand molds to gases [15]. Previous tests showed that molds produced using binder jetting process produces much more amount of gases during casting process [16]. The surface roughness for the pump bowl casted using 3D printed mold and core is better compared to conventionally casted pump bowl. As the sand used for both the processes is same, still we get better surface finish for 3D printed pump bowl compared to conventional sand casting. The average roughness of $3 \mathrm{D}$ printed pump bowl surface is $\sim 200 \mu \mathrm{m}$, in the same order particle size. In comparison, the roughness of conventional one is $\sim 500 \mu \mathrm{m}$.

As shown in Figs. 8a and 9a, for the 3D printed mold, there are four bumps on four side which are the called core print for self alignment. When the core are assembled over the drag, self alignment of the core prints is required. They are removed after by post machining process.

In terms of mechanical strength, in conventional sand casting we need to mix the sand and chemical binders in a mixer and then they are filled into the wooden mold box manually. The chemical reaction will bind the sand particles at room temperature. The bonding strength will be different at different height of mold box. In contrast, in case of 3D printing technology binders are sprayed on every layer. This will result in good bonding strength between sand particles. The bonding nature helps in increasing mechanical strength of particles and along with the strength it also overcomes some problems in conventional sand casting like porosity and leads to better surface finish as shown in Figure 9. 


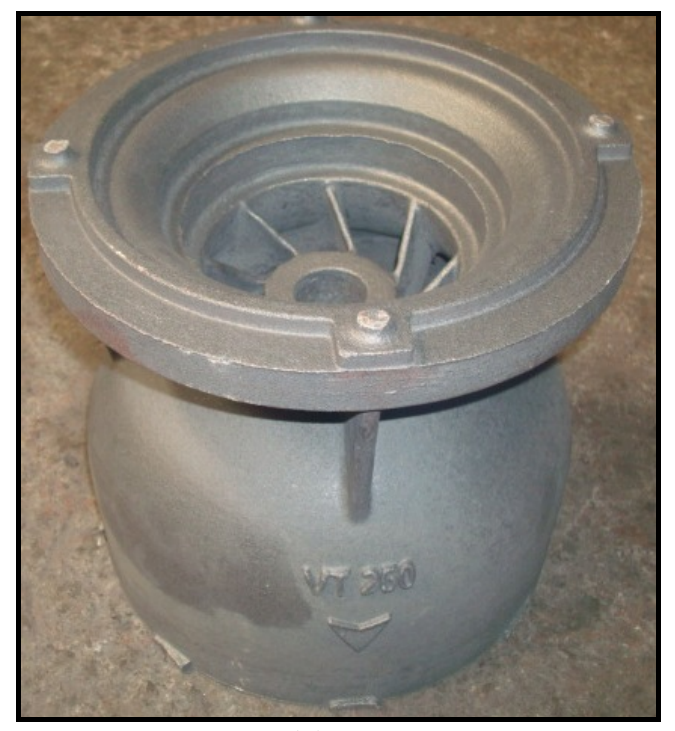

(a)

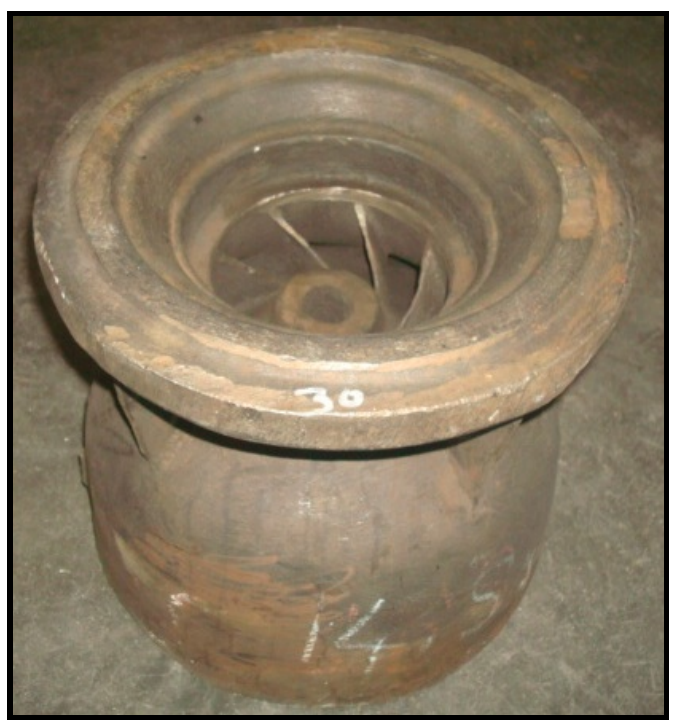

(b)

Fig.8: Side view of the fabricated pump bowl using: (a) 3D printed mold, (b) conventional sand casting mold.

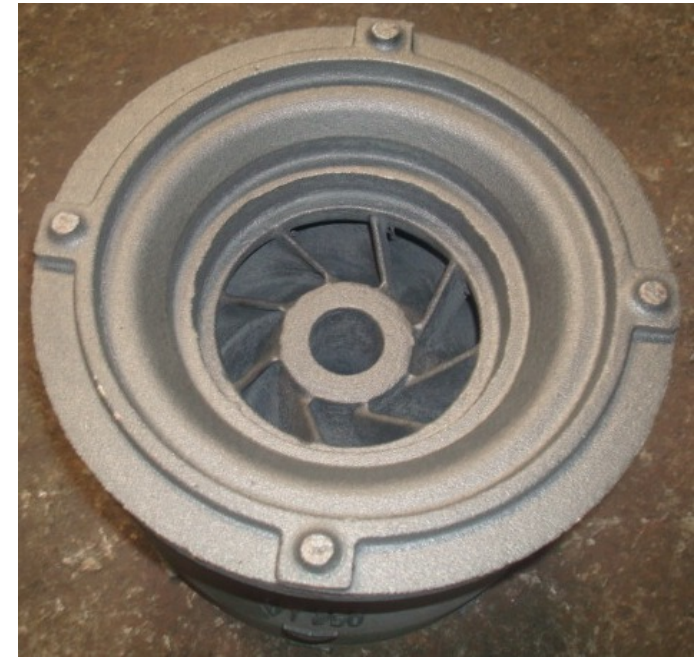

(a)

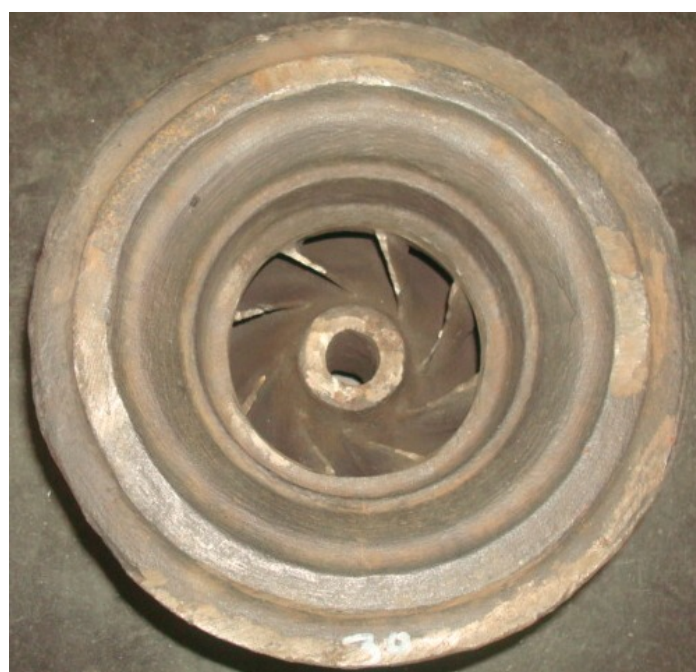

(b)

Fig.9: Top view of the fabricated pump bowl using: (a) 3D printed mold, (b) conventional sand casting mold.

\subsection{Design allowance}

Allowances are usually made in the core, mold, and pattern in order to compensate the dimensional changes that will happen during any step of the sand casting process[17]. The 
various types of allowances can be summarized by; the shrinkage allowances, the draft allowances, the shakeout allowances, the finishing or machining allowances and the distortion allowances. When metal cools down at room temperature, metal contraction is caused. To compensate the metal contraction, usually the pattern is made oversized, which increases the size of cavity made by pattern. As metal contraction occurs in every direction, the oversize allowance should be apply in each direction and depends on shape and size of the casting. As mentioned in Section 3.2, the surface roughness achieved for sand casting was $\sim 500 \mu \mathrm{m}$, and due to some surface impurities there are some surface variations. So in order to achieve better surface, finish machining is required to done, which can be compensated by providing machining allowances. The taper angle is provided on the pattern which is also called as draft angle, to reduce the damage to the edges while removing the pattern. This pattern allowance is known as draft allowance. As taper angle made by the pattern creates extra space, the required metal to pour also increases, which indirectly increases total weight of part cast.

As pattern making is eliminated in casting using 3D printed molds, the draft allowance will get eliminate. In case of $3 \mathrm{D}$ printing of sand, as the machine prints according to the CAD data provided, the possibility of getting good dimensional accuracy is more. So we can reduce the machining and finishing allowances. The only allowance which will contribute in total weight is shrinkage allowance. As pattern allowances are eliminated and machining allowances are reduced it will definitely lead to total weight reduction of the final part.

\subsection{Fettling work}

Fettling work includes removal of runners, risers and feeder head after the breaking out of mold by knocking off or rinsing away, or in some cases by means of gas cutters, saws, abrasive wheels. Fettling also involves dressing for the removal of excess metal and residual adhering sand. Some residuals of feeder heads and in-gates like flash, pads and stumps are also dressed during fettling. The fettling operation is carried out with taking care of shape, surface finish and dimensions of final cast with conform to design requirements [2].

For the casted pump bowl the hydraulic shape of vane tip achieved in conventional sand casting process was having extra metal on its vane tip because of the allowances given to it by considering casting design and metal characteristics. This extra metal was removed by fettling operation carried out by grinders which creates uneven surfaces causing loss of hydraulic 
accuracy. But in case of sand printing process we can keep close tolerances and less machining allowances. The fettling work required in sand printing is only removal of runner, risers and feeders. As we can achieve dimensional accuracy in sand printing, the last stage in fettling work i.e. removal of excess metal is reduced. The vane tip of pump bowl which we get in sand printing process is as per hydraulic design and requires less grinding which results in improved hydraulic accuracy.

\subsection{Comparison of two casting processes}

There are several major limitations in conventional sand casting process. Pattern, cores and mold making, therefore, are the life blood of the foundry business. Conventional sand casting starts with developing pattern for the part, as every new casting requires new pattern to make, so without pattern we cannot move further. Final design of the part is totally depended on pattern design, so any dimensional inaccuracy will affect final dimensions. On the other hand casting using additive manufacturing does not require any pattern. A mold with inbuilt gating system also eliminates manual gating which requires skilled labor in conventional sand casting. In conventional sand casting process, it is not possible to get casting as per the design data, i.e., the dimensions are always greater in some proportion. But on the other hand the casted pump bowl using 3D printed molds was as per design data. Table 3 shows the comparison summary of casted pump bowl using conventional sand casting and sand printing process. Comparison is done considering process requirements, time, cost and weight for both the processes. This comparison summary shows that the pump bowl casted using $3 \mathrm{D}$ printed molds is better over conventional sand casted pump bowl.

It is noted that the cost and lead time benefits of 3D printed sand casting mold are affected by the production volume. 3D printed sand casting molds should be more effective if only one or a small quantity of molds are needed. However, if a relatively larger quantity of molds are made, the traditional tooling based method may be more favorable.

Additionally, it is important to be aware of the costs of 3D printer and operation. Currently, the cost of the 3D printer is about $\$ 250.000$. The hourly rate in running the 3D printer and material supplies also need to be considered. 
Table 3: Comparison summary of two processes

\begin{tabular}{|c|c|c|}
\hline Process requirements & $\begin{array}{c}\text { Conventional sand casting } \\
\text { process }\end{array}$ & 3D printing process \\
\hline 3D CAD data & No & Yes \\
\hline Pattern / Core box required & Yes & No \\
\hline Gating system - CAD data & No & Yes \\
\hline Results depend on & Pattern equipment & Automation \\
\hline Mold \& Core making & Manual & Furan sand \\
\hline Core Sand material & No- bake & Furan sand \\
\hline Mold Sand material & No-bake & Consistent \\
\hline Repeatability & Depends on pattern condition & Not required \\
\hline Core making time (min) & 120 & No \\
\hline Mold Making time (min) & 120 & Fine \\
\hline Specific molding box & Yes & Yes \\
\hline Core \& mold finish & Less & Not required \\
\hline Core \& mold painting & Yes & No \\
\hline Skill manpower & Yes & Not required \\
\hline Dependency on manpower & Yes & high \\
\hline Pattern making time (month) & 3 & 3.3 \\
\hline Equipment, process \& materials & low & 99 \\
\hline costs & 7.7 & 23 \\
\hline Core weight(Kg) & 301 & 15 \\
\hline Mold weight(Kg) & 34 & \\
\hline Casting weight(design: $22.5 \mathrm{Kg})$ & 60 & \\
\hline Fettling time (min) & & \\
\hline
\end{tabular}

\section{CONCLUSIONS}

In this study, the two mold casting processes, conventional sand casting process and sand casting using $3 \mathrm{D}$ printed molds and core are systematically compared. The results of this study indicate significant advantages in employing additive manufacturing technology in the production of mold and core for pump bowl. These advantages include substantial cost and lead-time savings with minimal material wastage. The major conclusions are summarized below.

1. 3D printing process is more effective than conventional sand casting process, in terms of weight saving of sand, along with metal used, design allowances and fettling work, when a small quantity of molds is required. The traditional tooling based method may be more favorable when a relatively larger quantity of molds are made. Additionally, current costs of the $3 \mathrm{D}$ printer and operation are higher than the conventional approach. 
2. The 3D printed mold's surface quality achieved in this study is better than the conventional one, along with improved dimensional accuracy. This is due to 3D printed sand molds and core having close tolerance, which eliminates the pattern making operation in the conventional sand casting.

\section{Acknowledgements}

JZ acknowledges the financial support provided by Walmart Foundation (project title: Optimal Plastic Injection Molding Tooling Design and Production through Advanced Additive Manufacturing); Jin Sung Precision Metal Co., Ltd, Republic of Korea (project title: Development of ceramic core for fabricating $450 \mathrm{~mm}$ impeller with flow thickness of $4 \mathrm{~mm}$ based on 3D printing technology, and its commercialization technology); and the Korea Institute

of Energy Technology Evaluation and Planning (KETEP), with the financial resource from the Ministry of Trade, Industry \& Energy (MOTIE), Republic of Korea (No. 20172020108530). 


\section{References}

1. Banchhor, R. and S. Ganguly, Optimization in green sand casting process for efficient, economical and quality casting. Int J Adv Engg Tech/Vol. V/Issue I/Jan.-March, 2014. 25: p. 29.

2. Beeley, P., Foundry Technology (Second Edition). 2 ed. 2001, Oxford: ButterworthHeinemann. 719.

3. Campbell, J., Castings. 2. ed. 2003, Burlington, Mass.: Butterworth Heinemann. 352p.

4. Wang, W., H.W. Stoll, and J.G. Conley, Rapid Tooling Guidelines For Sand Casting. 1 ed. Mechanical Engineering Series. 2010: Springer US. XIV, 164.

5. Kalpakjian, S. and S. Schmid, Manufacturing Processes for Engineering Materials. 5th ed. 2008: Pearson Education. 1040pp.

6. Meisel, N.A., C.B. Williams, and A. Druschitz. Lightweight metal cellular structures via indirect $3 D$ printing and casting.

7. Frank, M.C., et al. A Hybrid Rapid Pattern Manufacturing System for Sand Castings.

8. Chua, C.K., S.M. Chou, and T.S. Wong, A study of the state-of-the-art rapid prototyping technologies. The International Journal of Advanced Manufacturing Technology, 1998. 14(2): p. 146-152.

9. $\quad$ Song, J.L., et al., Rapid prototyping manufacturing of silica sand patterns based on selective laser sintering. Journal of Materials Processing Technology, 2007. 187-188: p. 614-618.

10. M.M. Akarte and B. Ravi, RP/RT Route Selection for Casting Pattern Development All IndiaManufacturing Technology, Design and Research Conference, 2010: p. 8.

11. Dean Snelling, et al., The Effects of 3d Printed Molds on MetalCastings. Solid Freeform Fabrication Symposium, 2013: p. 827-845.

12. Holtzer, M., M. Górny, and R. Dańko, Microstructure and Properties of Ductile Iron and Compacted Graphite Iron Castings. 1 ed. SpringerBriefs in Materials. 2015: Springer International Publishing. XII, 158.

13. Material data sheet for Furan-Direct-Binding (FDB) sand molds. 2016; Available from: http://www.voxeljet.com/materials/sand/.

14. Ederer, I. and R. Hochsmann, Rapid-prototyping method and apparatus, U.S. Patent, Editor. 2005, VoXeljet Technology GmbH, Augsburg (DE): USA. p. 17.

15. Nwaogu, U.C. and N.S. Tiedje, Foundry coating technology: a review. Materials Sciences and Applications, 2011. 2(08): p. 1143.

16. Snelling, D. Mitigating Gas Defects in Castings Produced from 3D Printed Molds. in 117th Metalcasting Congress. 2013. Afsinc.

17. Peters, F., et al., Effect of mould expansion on pattern allowances in sand casting of steel. International Journal of Cast Metals Research, 2008. 20(5): p. 275-287. 